\begin{tabular}{|c|l|}
\hline Title & Enhanced production of p24 Gag protein in HIV-1-infected rat cells fused with uninfected human cells. \\
\hline Author(s) & $\begin{array}{l}\text { Chen, Jing; Zhao, X Udong; Lai, Y urong; Suzuki, A kira; Tomaru, Utano; Ishizu, A kihiro; Takada, A kio; Ikeda, Hitoshi; } \\
\text { Kasahara, Masanori; Y oshiki, Takashi }\end{array}$ \\
\hline Citation & $\begin{array}{l}\text { Experimental and Molecular Pathology, 83(1), 125-130 } \\
\text { https://doi.org/10.1016/.yexmp.2006.11.003 }\end{array}$ \\
\hline Issue Date & 2007-08 \\
\hline Doc URL & http://hdl.handle.net/2115/28263 \\
\hline Type & article (author version) \\
\hline File Information & EMP83-1.pdf \\
\hline
\end{tabular}

Instructions for use 


\title{
Enhanced production of p24 Gag protein in HIV-1-infected rat cells fused with uninfected human cells
}

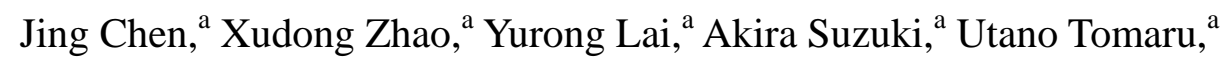 \\ Akihiro Ishizu, ${ }^{\mathrm{a}, \mathrm{b}, *}$ Akio Takada, ${ }^{\mathrm{a}, \mathrm{c}}$ Hitoshi Ikeda, ${ }^{\mathrm{a}}$ Masanori Kasahara, ${ }^{\mathrm{a}}$ \\ Takashi Yoshiki ${ }^{\text {a,d }}$ \\ ${ }^{\mathrm{a}}$ Department of Pathology, Hokkaido University Graduate School of Medicine, \\ Sapporo 060-8638, Japan \\ ${ }^{\mathrm{b}}$ Department of Health Sciences, Hokkaido University School of Medicine, \\ Sapporo 060-0812, Japan \\ 'Sapporo City General Hospital, Sapporo 060-8604, Japan \\ ${ }^{\mathrm{d}}$ Genetic Lab, Sapporo 060-0009, Japan
}

\footnotetext{
*Corresponding author. Department of Health Sciences, Hokkaido University School of Medicine, Kita-12, Nishi-5, Kita-ku, Sapporo 060-0812, Japan.

Tel: +81-11-706-3696, Fax: +81-11-706-4916, E-mail address: aishizu@med.hokudai.ac.jp (A. Ishizu)
} 


\begin{abstract}
Although many human molecules have been suggested to affect replication of human immunodeficiency virus type 1 (HIV-1), the distribution of such cofactors in human cell types is not well understood. Rat W31/D4R4 fibroblasts expressing human CD4 and CXCR4 receptors were infected with HIV-1. The provirus was integrated in the host genome, but only a limited amount of p24 Gag protein was produced in the cells and culture supernatants. Here we found that p24 production was significantly increased by fusing HIV-1-infected W31/D4R4 cells with uninfected human cell lines of T-cell, B-cell, or macrophage lineages. These findings suggest that human cellular factors supporting HIV-1 replication are distributed widely in cells of lymphocyte and macrophage lineages. We also examined whether the amount of p24 produced by rat-human hybrid cells was correlated with expression levels of specific human genes. The results suggested that HP68 and MHC class II transactivator (CIITA) might up- and down-regulate p24 production, respectively. It was also suggested that HIV-1 replication is affected by molecules other than those examined in this study, namely, cyclin T1, cyclin-dependent kinase 9, CRM1, HP68, and CIITA.
\end{abstract}

Keywords: HIV-1; rat model; cell fusion; cyclin T1; CDK9; CRM1; HP68; CIITA 


\section{Introduction}

Replication of human immunodeficiency virus type 1 (HIV-1) is initiated by binding of the viral envelope to the specific surface receptors on target cells. The viral envelope gp120 glycoprotein binds to a human CD4 molecule expressed on $\mathrm{T}$ cells and macrophages. A chemokine receptor CXCR4 on T cells or CCR5 on macrophages is also required for virus entry into cells (Kozak et al., 1997). CD4 molecules and chemokine receptors of rodents, which are naturally resistant to HIV-1 infection, do not bind to gp120; therefore, a major barrier to HIV-infection exists at the level of virus entry (Pleskoff et al., 1997). Recent studies showed that rat-derived cells expressing human CD4 and CXCR4 or CD4 and CCR5 became susceptible to HIV-1 viruses (Keppler et al., 2001). However, the rat cell lines produced infectious virus particles still at much lower levels than in human cells, suggesting the existence of additional human factors important for HIV-1 replication.

Over the past couple of decades, several critical steps in HIV-1 replication have been identified. HIV-1 gene expression relies upon complex machinery controlled by two viral regulatory proteins, Tat and Rev. Tat activates the transcription of the viral genome and requires the cellular protein kinase activity termed TAK/P-TEFb, composed of cyclin $\mathrm{T} 1$ and cyclin-dependent kinase 9 (CDK9), for its transactivation function (Herrmann and Rice, 1995; Chen et al., 1999). It is reported that the host MHC class II transactivator (CIITA) is recruited instead of Tat during an early phase of infection (Saifuddin et al., 2000). Rev is necessary for the accumulation of incompletely spliced HIV-1 RNAs in the nucleus, and exports them to the cytoplasm cooperating with the cellular exportin 1/CRM1 molecule (Cmarko et al., 2002). During HIV-1 assembly, Gag polypeptides multimerize into immature HIV-1 capsids. The cellular ATP-binding protein, HP68, is required for this process (Zimmerman et al., 2002; Lingappa et al., 2006). 
Although many human molecules have been suggested to affect HIV-1 infection and replication, the distribution of such cofactors in human cell types is not well understood. Here we infected rat fibroblasts coexpressing human CD4 and CXCR4 with HIV-1, fused them with uninfected human cell lines of T-cell, B-cell, or macrophage lineages, and then examined virus production and expression profiles of human genes in the fused cells.

\section{Materials and methods}

Cells

Rat W31 fibroblasts (Kanki et al., 2000) were transfected with plasmids carrying the human CD4 gene and those carrying the CXCR4 gene. The expression plasmid of the human CD4 gene (Yamamura et al., 1991) was kindly provided by Dr. Karasuyama (Tokyo Medical and Dental University, Tokyo, Japan). The CXCR4 cDNA was amplified using total RNAs extracted from human peripheral blood mononuclear cells, and then subcloned into the pcDNA3.1/Zeo vector (Invitrogen, Carlsbad, CA). Transfection was carried out using Lipofectamine (Invitrogen) according to the manufacturer's protocol. The transfectant, designated as W31/D4R4 cells, was maintained in DMEM supplemented with $10 \%$ fetal calf serum (FCS), $400 \mu \mathrm{g} / \mathrm{ml}$ of G418 (GIBCO-BRL, Rockville, MD), and $40 \mu \mathrm{g} / \mathrm{ml}$ of Zeocine (Invitrogen). Several weeks later, cloned W31/D4R4 cells were obtained with limiting dilution.

Human cell lines, including Hut78 and Jurkat (T-cell lymphoma), U937 (macrophage-like cell line), and GI, Raji, Swei, and WT46 (B-cell lymphoma), were cultured in RPMI 1640 medium supplemented with 10\% FCS. 


\section{HIV-1 infection}

W31/D4R4 cells $\left(5 \times 10^{5}\right)$ were pretreated with $2 \mu \mathrm{g} / \mathrm{ml}$ of polybrene for $30 \mathrm{~min}$, and then the T-tropic HIV-1 strain, SF33 (Tateno et al., 1988), was applied to the cells (equivalent to $200 \mathrm{ng}$ of p24 Gag protein) followed by incubation for 3 hours at $37^{\circ} \mathrm{C}$. The supernatants were then removed, and cells were washed 3 times with PBS and digested by trypsin to remove viruses that had not entered the cells. The cells were resuspended in the selection medium and cultured at $37^{\circ} \mathrm{C}$.

\section{PCR and RT-PCR for HIV-1 genes}

Genomic DNAs were extracted from the HIV-1-infected W31/D4R4 cells by the standard method. Total RNAs were extracted from the cells with TRIzol Reagent (Invitrogen). The RNAs were subjected to DNase I treatment to remove contaminating DNAs. cDNAs were synthesized with $4 \mu \mathrm{g}$ of the DNase-treated RNAs using the SuperScript III kit (Invitrogen). PCR for HIV-1 genes was performed using primer sets described previously (York-Higgins et al., 1990; Brandt et al., 1992).

\section{ELISA for p24 Gag protein}

HIV-1 p24 Gag protein was quantified using the p24 assay ELISA kit (Zeptometrix, Buffalo, NY). Culture supernatants and cell lysates were subjected to this assay. Tissue culture medium was changed with fresh one 24 hours prior to the assay. The supernatants were centrifuged to remove cell debris; $450 \mu$ l of the solution was taken and then mixed with $50 \mu \mathrm{l}$ of the lysis buffer appended to the kit. The resultant mixture served as culture supernatant samples. For cell lysate samples, $1 \times 10^{7}$ cells were resuspended in $450 \mu \mathrm{l}$ of fresh medium, and then mixed well with $50 \mu \mathrm{l}$ of the lysis buffer. After centrifugation for removal of the pellets, the supernatants were used as cell lysate samples. 


\section{Cell fusion}

HIV-1-infected W31/D4R4 cells were maintained for 3 months. Cells $\left(5 \times 10^{6}\right)$ were then washed extensively with PBS, digested by trypsin, and mixed with an equal number of human cells. The mixed cell pellets were overlaid with $1 \mathrm{ml}$ of a $50 \%$ solution of polyethylene glycol, and stirred gently. After incubation at $37^{\circ} \mathrm{C}$ for $1 \mathrm{~min}$, PBS was added slowly followed by centrifugation (500 $\mathrm{g}$ for $5 \mathrm{~min}$ ) to remove supernatants. The pellets were resuspended in the selection medium and incubated at $37^{\circ} \mathrm{C}$. The medium was changed with fresh one every 3 or 4 days. Three weeks later, p24 concentrations were determined in the fused cells and culture supernatants, and the expression of human genes in the rat-human hybrid cells was examined by RT-PCR (see “RT-PCR for human genes”).

To evaluate the efficiency of cell fusion, human cells were labeled with PKH26 Red Fluorescent Cell Linker Kit (Sigma-Aldrich, St. Louis, MO), according to the manufacturer's protocol, prior to cell fusion. The labeled cells were then fused with uninfected W31/D4R4 cells as described above. Fused cells were incubated in the selection medium at $37^{\circ} \mathrm{C}$ for 1 week. The percentage of fused cells was calculated by dividing the number of fluorescence-labeled cells by that of living cells.

\section{RT-PCR for human genes}

Expression of human genes, including cyclin T1, CDK9, CRM1, HP68, and CIITA, was examined by RT-PCR. Hybrid cells were harvested 21 days after fusion, and total RNAs were extracted and then subjected to cDNA synthesis. cDNAs were also prepared from parental human cells that were not subjected to fusion with W31/D4R4 cells. The first round of PCR was run for 15 cycles $\left(95^{\circ} \mathrm{C}\right.$ for $30 \mathrm{sec}$, annealing for 30 sec, $72^{\circ} \mathrm{C}$ for $30 \mathrm{sec}$ ) with sense 1 and antisense 1 primers. The second round of PCR 
was run for 35 cycles $\left(95^{\circ} \mathrm{C}\right.$ for $30 \mathrm{sec}$, annealing for $30 \mathrm{sec}, 72^{\circ} \mathrm{C}$ for $\left.30 \mathrm{sec}\right)$ with sense 2 and antisense 2 primers. Primer sequences and the annealing temperature are shown in Table 1. These primer sets were specific for the human genes and did not amplify the corresponding rat genes.

\section{Statistics}

Data were analyzed with Student's $t$-test. P-values less than 0.05 were considered to be significant.

\section{Results}

Integration and expression of viral genes in W31/D4R4 cells infected with HIV-1

W31/D4R4 cells were infected with the T-tropic HIV-1 strain, SF33. Three months later, genomic DNAs and total RNAs were extracted from the HIV-1-infected cells, and then integration of provirus and expression of viral mRNAs were examined by PCR and RT-PCR, respectively.

Integration of HIV-1 provirus was confirmed by PCR with 5 pairs of primers, each specific for the gag, pol, vif, tat, or env region of the HIV-1 genome (Fig. 1A). Expression of viral mRNAs, including gag, pol, vif, tat, and env, was detected by RT-PCR (Fig. 1B). By contrast, RNAs without reverse transcription did not generate visible PCR products, indicating minimal contamination of genomic DNAs in the RNA sample (data not shown). These findings suggested that W31/D4R4 cells were infected with HIV-1, and that integration of provirus was accomplished and viral mRNAs were expressed in the rat cells. 


\section{Production of p24 Gag protein in W31/D4R4 cells infected with HIV-1}

We examined the production of viral proteins in HIV-1-infected W31/D4R4 cells by measuring p24 Gag concentrations in the cell lysates and culture supernatants. Samples were collected at days 2, 4, 7, 14, 21, and 28 post-infection, and the amount of HIV-1 Gag protein was measured using the p24 ELISA kit. p24 in the cell lysates showed a peak concentration of $>10,000 \mathrm{pg} / \mathrm{ml}$ at day 4 post-infection, and decreased to $84 \mathrm{pg} / \mathrm{ml}$ at day 28 post-infection (Fig. 2). Even 3 months later, p24 in the cell lysates retained a concentration of $12 \mathrm{pg} / \mathrm{ml}$ (data not shown). On the other hand, p24 in the supernatants showed a peak concentration of $>1,000 \mathrm{pg} / \mathrm{ml}$ at day 4 post-infection, but decreased rapidly, and fell below the detection limit at day 28 post-infection.

\section{Production of p24 Gag protein in fused cells}

Three months after HIV-1 infection, the infected W31/D4R4 cells were fused with human cell lines. Cell lysates and culture supernatants were subjected to ELISA at day 21 after cell fusion. p24 concentration in the cell lysates showed a 4-10 fold increase when the HIV-1-infected W31/D4R4 cells were fused with an uninfected human T-cell lymphoma line Hut 78, a macrophage-like cell line U937, and B-cell lymphoma lines GI, Swei, and WT 46 (Fig. 3A). Although there was no statistically significant difference, fusion with the B-cell lymphoma line Raji also increased the concentration of p24 in the cell lysates. On the other hand, no significant increase was seen when HIV-1-infected W31/D4R4 cells were fused with the human T-cell lymphoma line Jurkat.

Fusion with human cells generally failed to increase p24 concentration in the culture supernatants (Fig. 3B). However, p24 concentration showed a slight but statistically significant increase $(10 \mathrm{pg} / \mathrm{ml})$ when the HIV-1-infected W31/D4R4 cells were fused with the B-cell lymphoma line WT46. 


\section{Alteration of human gene expression after cell fusion}

Expression of human cyclin T1, CDK9, CRM1, HP68, and CIITA genes was examined by RT-PCR in both parental human cell lines and rat-human hybrid cells. For this analysis, we used the same batch of hybrid cells as used in Figure 3. Cyclin T1, CDK9, CRM1, and HP68 genes were expressed in all the human cell lines examined (Fig. 4, left panels). Notably, expression of CIITA was not detected in Jurkat (see asterisk).

After cell fusion, expression of human genes was largely extinguished (Fig. 4, right panels). None of the hybrid cells expressed human CDK9 or CRM1. Expression of cyclin T1 was seen exclusively in W31/D4R4 cells fused with Raji, and HP68 was expressed only in W31/D4R4 cells fused with WT46. The human CIITA gene, expressed in Hut78, U937, and the B-cell lymphoma lines, lost its expression after fusion. On the contrary, expression of CIITA was induced in W31/D4R4-Jurkat hybrid cells.

\section{Discussion}

Development of a small animal model of HIV-1 infection would greatly facilitate studies of virus transmission, pathogenesis, host immune responses, and antiviral strategies. Mice and rats are attractive models for HIV-1 study because they can be genetically manipulated. However, the development of a permissive model has been hampered by the inability of HIV-1 to infect primary rodent cells.

Rodent CD4 and CXCR4/CCR5 (receptors for HIV-1) do not bind to the viral envelope gp120 (Pleskoff et al., 1997). Transgenic mouse and rat cells, expressing human CD4 and CXCR4 or CD4 and CCR5, became susceptible to HIV-1 infection, 
and the provirus could be integrated in the host genome (Sawada et al., 1998; Keppler et al., 2001). However, replication of the infectious virus remained at much lower levels in these rodent cells than in human cells, thus suggesting the involvement of additional human genes in virus replication (Freed, 2004; Trkola, 2004). Indeed, it has been reported that human but not rodent cyclin T1 supports the function of viral Tat protein (Keppler et al., 2001). One of the effective ways to identify human molecules contributing to HIV-1 replication is to conduct cell fusion experiments using human and rodent cells. Identification of such molecules and subsequent introduction into rodents should help us establish animal models of HIV-1 infection.

Although several human molecules have been suggested to affect HIV-1 replication, the distribution of such cofactors in human cell types is not well understood. In the present study, rat fibroblasts transgenic for human CD4 and CXCR4 genes, W31/D4R4, were infected with HIV-1. These cells were fused with uninfected human cell lines of T-cell, B-cell, or macrophage origin, followed by the assessment of associations between viral production and human gene expression.

As expected, rat W31/D4R4 cells could be infected with HIV-1, and the provirus was integrated in the host genome (Fig. 1A). Expression of virus genes was detectable by RT-PCR even 3 months after infection (Fig. 1B), but the concentration of p24 Gag protein was very low in the cell lysates $(12 \mathrm{pg} / \mathrm{ml})$ and was below the detection limit in the culture supernatants (Fig. 2). Poor production of p24 may have occurred because rat cells infected with HIV-1 died or were unable to proliferate like their uninfected counterparts, and/or because host factors supporting viral replication were deficient in rat cells. Since we observed no significant difference in the viability and proliferation of W31/D4R4 cells before and after HIV-1 infection, the first possibility appeared unlikely. Thus, we conducted cell fusion experiments using HIV-1-infected W31/D4R4 cells and uninfected human cell lines. 
We found significant recovery of the expression of p24 Gag protein in the HIV-1-infected W31/D4R4 cells upon fusion with the human T-cell lymphoma line Hut78, macrophage-like cell line U937, and B-cell lymphoma lines GI, Swei, and WT46 (Fig. 3A). These findings indicate that human factors that support HIV-1 replication are distributed widely in cells of lymphocyte and macrophage lineages.

To examine whether the amount of p24 produced by hybrid cells is correlated with expression levels of specific human genes, we analyzed expression of cyclin T1, CDK9, CRM1, HP68, and CIITA genes in the fused cells. We chose these genes for study because they have been suggested to affect HIV-1 replication (Herrmann and Rice, 1995; Chen et al., 1999; Saifuddin et al., 2000; Cmarko et al., 2002; Zimmerman et al., 2002; Lingappa et al., 2006). As shown in Figure 4, expression of most human genes was lost or down-regulated after cell fusion. By contrast, expression of rat genes coding for cyclin T1, CDK9, CRM1, HP68, and CIITA was not altered (data not shown). These observations indicate that human genes are preferentially lost or inactivated by cell fusion. Some hybrid cells ceased to express all of the human genes examined, but still showed increased production of p24. This suggests that human molecules that facilitate HIV-1 replication are not limited to cyclin T1, CDK9, CRM1, HP68, and CIITA. There may be unknown human molecules that compensate for the loss of cyclin T1, CDK9, CRM1, HP68, and CIITA and promote HIV-1 replication.

Interestingly, fusion with Jurkat cells consistently failed to increase p24 production. This was not because the efficiency of cell fusion was low in Jurkat, since we confirmed that all of the human cell lines examined in this study fused with W31/D4R4 cells with almost the same efficiency (data not shown). It was initially reported that CIITA might promote HIV-1 replication by functioning as a substitute of Tat during an initial post-infection period (Saifuddin et al., 2000). However, more recent work indicates that overexpression of CIITA inhibits viral replication by blocking 
the function of Tat (Okamoto et al, 2000; Accolla et al., 2002). In this regard, it is interesting to note that human CIITA, which was not expressed in Jurkat, began to be expressed after fusion with rat cells. Transcriptional induction of CIITA might be involved in poor production of p24 in W31/D4R4-Jurkat hybrid cells.

A slight but significant increase in p24 concentration $(10 \mathrm{pg} / \mathrm{ml})$ was found in the supernatants of W31/D4R4-WT46 hybrid cells (Fig. 3B). Interestingly, expression of human HP68 was detected only in this hybrid cells. These results are consistent with the previous reports that human HP68 is a cellular protein important for capsid assembly (Zimmerman et al., 2002; Lingappa et al., 2006). Based on these findings, we suggest that introduction of human HP68 should be considered when designing animal models of HIV-1 infection.

In summary, we performed cell fusion experiments using HIV-1-infected rat fibroblasts and uninfected human cell lines of T-cell, B-cell, and macrophage lineages. Our results indicate that human cellular factors supporting HIV-1 replication are distributed in all of these cell lineages. Identification of additional factors affecting HIV-1 replication, the presence of which was suggested by the cell fusion experiments (Fig. 4), would be important to understand the replication cycle of HIV-1 and to develop countermeasures to control HIV-1 infection.

\section{Acknowledgments}

This work was supported by a grant from The Japan Society for the Promotion of Science. 


\section{References}

Accolla, R.S., Mazza, S., De Lerma, Barbaro, A., De Maria, A., Tosi, G. 2002. The HLA class II transcriptional activator blocks the function of HIV-1 Tat and inhibits viral replication. Eur. J. Immunol. 32, 2783-2791.

Brandt, C.D., Rakusan, T.A., Sison, A.V., Josephs, S.H., Saxena, E.S., Herzog, K.D., Parrott, R.H., Sever, J.L. 1992. Detection of human immunodeficiency virus type 1 infection in young pediatric patients by using polymerase chain reaction and biotinylated probes. J. Clin. Microbiol. 30, 36-40.

Chen, D., Fong, Y., Zhou, Q., 1999. Specific interaction of Tat with the human but not rodent $\mathrm{P}$-TEFb complex mediates the species-specific Tat activation of HIV-1 transcription. Proc. Natl. Acad. Sci. USA 96, 2728-2733.

Cmarko, D., Boe, S.O., Scassellati, C., Szilvay, A.M., Davanger, S., Fu, X.D., Haukenes, G., Kalland, K.H,, Fakan, S., 2002. Rev inhibition strongly affects intracellular distribution of human immunodeficiency virus type 1 RNAs. J. Virol. 76, 10473-10484.

Freed, E.O. 2004. HIV-1 and the host cell: an intimate association. Trends Microbiol. 12, 170-177.

Herrmann, C.H., Rice, A.P., 1995. Lentivirus Tat proteins specifically associate with a cellular protein kinase, TAK, that hyperphosphorylates the carboxyl-terminal domain of the large subunit of RNA polymerase II: candidate for a Tat cofactor. J. Virol. 69, $1612-1620$. 
Kanki, K., Torigoe, T., Hirai, I., Sahara, H., Kamiguchi, K., Tamura, Y., Yagihashi, A., Sato, N., 2000. Molecular cloning of rat NK target structure-the possibility of CD44 involvement in NK cell-mediated lysis. Microbiol. Immunol. 44, 1051-1061.

Keppler, O.T., Yonemoto, W., Welte, F.J., Patton, K.S., Iacovides, D., Atchison, R.E., Ngo, T., Hirschberg, D.L., Speck, R.F., Goldsmith, M,A., 2001. Susceptibility of rat-derived cells to replication by human immunodeficiency virus type 1. J. Virol. 75, 8063-8073.

Kozak, S.L., Platt, E.J., Madani, N., Ferro, F.E. Jr., Peden, K., Kabat, D., 1997. CD4, CXCR-4, and CCR-5 dependencies for infections by primary patient and laboratory-adapted isolates of human immunodeficiency virus type 1. J. Virol. 71, 873-882.

Lingappa, J.R., Dooher, J.E., Newman, M.A., Kiser, P.K., Klein, K.C., 2006. Basic residues in the nucleocapsid domain of Gag are required for interaction of HIV-1 Gag with ABCE1 (HP68), a cellular protein important for HIV-1 capsid assembly. J. Biol. Chem. 281, 3773-3784.

Okamoto, H., Asamitsu, K., Nishimura, H., Kamatani, N., Okamoto, T. 2000. Reciprocal modulation of transcriptional activities between HIV-1 Tat and MHC class II transactivator CIITA. Biochem. Biophys. Res. Commun. 279, 494-499.

Pleskoff, O., Sol, N., Labrosse, B., Alizon, M., 1997. Human immunodeficiency virus strains differ in their ability to infect CD4+ cells expressing the rat homolog of CXCR-4 
(fusin). J. Virol. 71, 3259-3262.

Saifuddin, M., Roebuck, K.A., Chang, Ch, Ting, J.P., Spear, G.T., 2000. Cutting edge: activation of HIV-1 transcription by the MHC class II transactivator. J. Immunol. 164, 3941-3945.

Sawada, S., Gowrishankar, K., Kitamura, R., Suzuki, M., Suzuki, G., Tahara, S., Koito, A. 1998. Disturbed CD4+ $\mathrm{T}$ cell homeostasis and in vitro HIV-1 susceptibility in transgenic mice expressing T cell line-tropic HIV-1 receptors. J. Exp. Med. 187, 1439-1449.

Tateno, M., Levy, J.A. 1988. MT-4 plaque formation can distinguish cytopathic subtypes of the human immunodeficiency virus (HIV). Virology 167, 299-301.

Trkola, A. 2004. HIV-host interactions: vital to the virus and key to its inhibition. Curr. Opin. Microbiol. 7, 407-411.

Yamamura, Y., Kotani, M., Chowdhury, M.I., Yamamoto, M., Yamaguchi, K., Karasuyama, H., Katsura, Y., Miyasaka, M. 1991. Infection of human CD4+ rabbit cells with HIV-1: the possibility of the rabbit as a model for HIV-1 infection. Int. Immunol. 3, 1183-1187.

York-Higgins, D., Cheng-Mayer, C., Bauer, D., Levy, J.A., Dina, D. 1990. Human immunodeficiency virus type 1 cellular host range, replication, and cytopathicity are linked to the envelope region of the viral genome. J. Virol 64, 4016-4020. 
Zimmerman, C., Klein, K.C., Kiser, P.K., Singh, A.R., Firestein, B.L., Riba, S.C., Lingappa, J.R., 2002. Identification of a host protein essential for assembly of immature HIV-1 capsids. Nature 415, 88-92. 
Table 1. Primers used for RT-PCR

\begin{tabular}{|c|c|c|c|}
\hline \multicolumn{2}{|c|}{ Name of genes } & Sequences (5' to $3^{\prime}$ ) & Annealing temperature \\
\hline \multirow[t]{3}{*}{ cyclinT1 } & Sense $1(2)^{*}$ & agctggaaaatagcccatcc & $60^{\circ} \mathrm{C}$ \\
\hline & Antisense 1 & aggaggttctgatggcagag & \\
\hline & Antisense 2 & ctgctggagccacagaattt & \\
\hline \multirow[t]{3}{*}{ CDK9 } & Sense 1 & gccaagatcggccaaggcaccttcgg & $56^{\circ} \mathrm{C}$ \\
\hline & Sense 2 & ggtgttcaaggccaggcaccgca & \\
\hline & Antisense $1(2)^{*}$ & cccatcacgagtgataagcacatta & \\
\hline \multirow[t]{3}{*}{ CRM1 } & Sense 1 & tgttggagcaagtaggaccag & $55^{\circ} \mathrm{C}$ \\
\hline & Sense 2 & gcaatgcatgaagaggacga & \\
\hline & Antisense $1(2)^{*}$ & cctgaacctgaacgaaatgc & \\
\hline \multirow[t]{4}{*}{ HP68 } & Sense 1 & gagttgtcctgtagttcgaatc & $55^{\circ} \mathrm{C}$ \\
\hline & Sense 2 & gtacgatgatcctcctgactggc & \\
\hline & Antisense 1 & aactctcctcctgaaagatcttca & \\
\hline & Antisense 2 & tcgttcttttaggtgggttaaatca & \\
\hline \multirow[t]{3}{*}{ CIITA } & Sense $1(2)^{*}$ & ctgggattcctacacaatgcg & $60^{\circ} \mathrm{C}$ \\
\hline & Antisense 1 & ctgggatcatctcaggctga & \\
\hline & Antisense 2 & tcagcatcgctgttaagaagctc & \\
\hline
\end{tabular}

*The same primer was used for the first and second rounds of PCR. 


\section{Figure legend}

Fig. 1. Integration of the provirus (A) and expression of viral mRNAs (B). W31/D4R4 cells were infected with HIV-1. Genomic DNAs and total RNAs were extracted from the cells 3 months after infection, and then integration of the provirus and expression of viral mRNAs were examined by PCR and RT-PCR, respectively. Ovals indicate specific PCR products. Product size: gag, 213 bp; pol, 307 bp; vif, 321 bp; tat, 159 bp; and env, 321 bp. M, 100-bp ladder marker.

Fig. 2. Production of p24 in HIV-1-infected W31/D4R4 cells. W31/D4R4 cells were infected with HIV-1. Cell lysates and culture supernatants were collected at days 2, 4, 7, 14, 21, and 28 post-infection, and the amount of HIV-1 p24 Gag protein was measured using the ELISA kit.

Fig. 3. Production of p24 in HIV-1-infected W31/D4R4 cells fused with uninfected human cells. HIV-1-infected W31/D4R4 cells were fused with indicated human cells. Cell lysates (A) and culture supernatants (B) were subjected to ELISA at day 21 after fusion. $\quad\left({ }^{*} \mathrm{p}<0.05\right)$

Fig. 4. Expression profiles of human genes in parental human cell lines (left) and hybrid cells (right). Expression of cyclin T1, CDK9, CRM1, HP68 and CIITA was examined by RT-PCR. Human cell lines were fused with HIV-1-infected W31/D4R4 cells. Total RNAs from hybrid cells were extracted at day 21 after fusion. The same hybrid cells were used for analysis in Figures 3 and 4. The asterisk indicates that Jurkat cells did not express detectable amounts of CIITA. Ovals indicate specific PCR products. M, 100-bp ladder marker. 


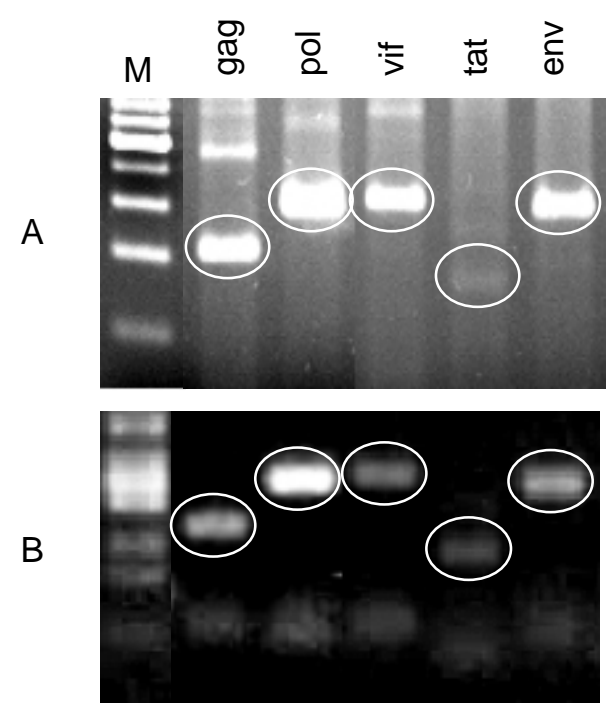

Figure 1 


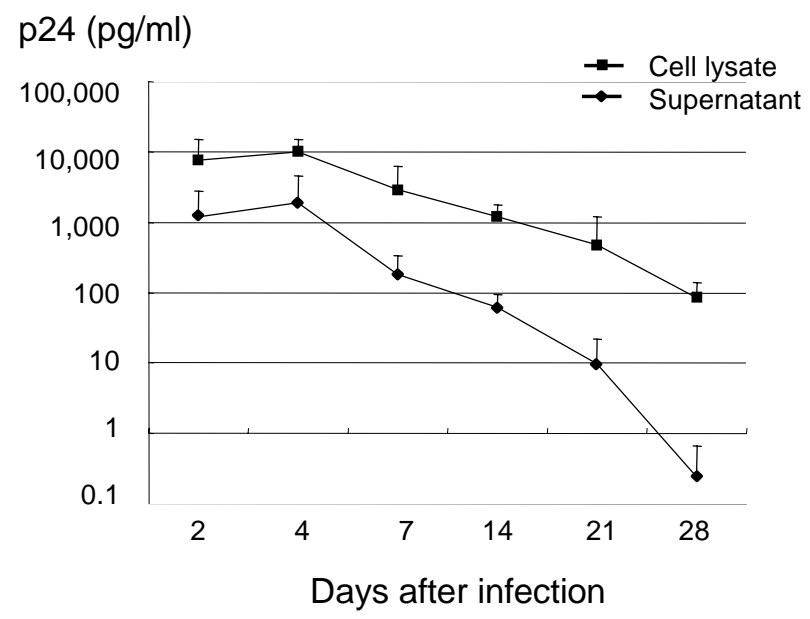

Figure 2 

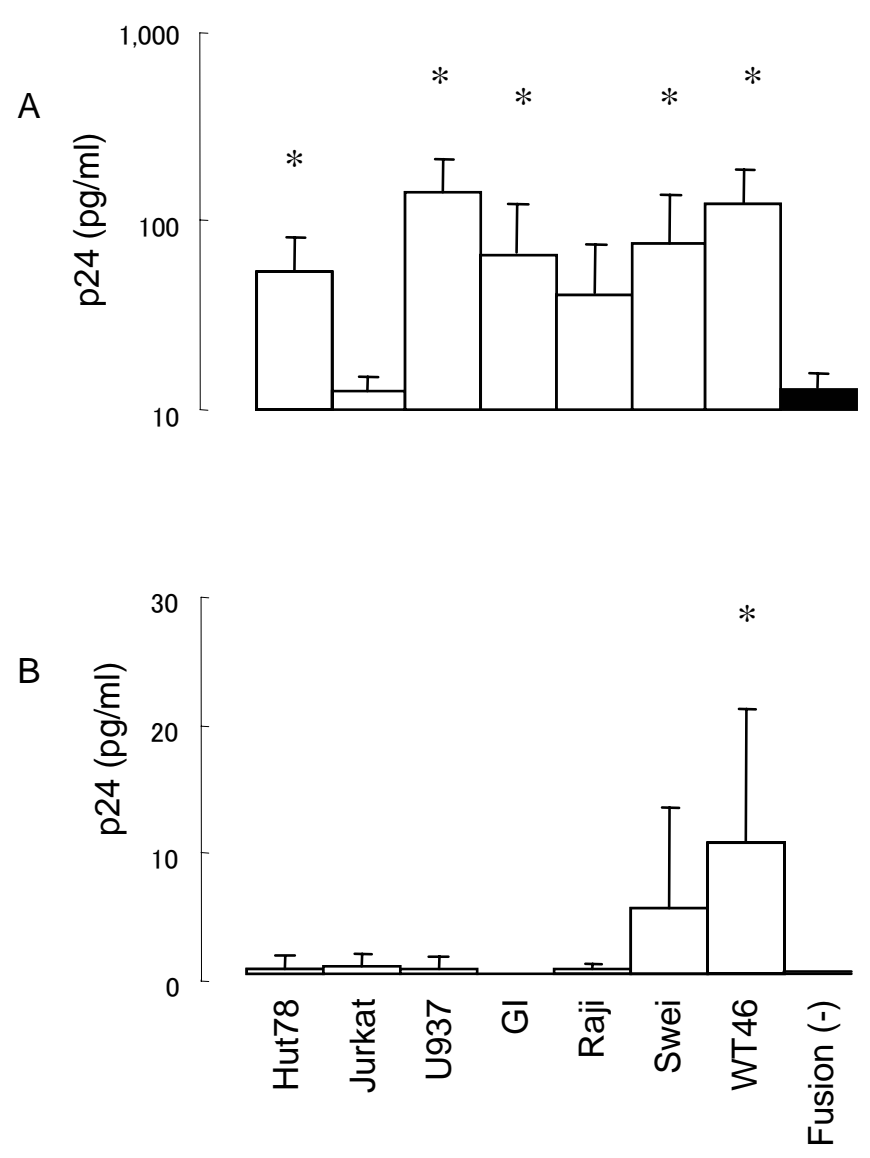

Figure 3 

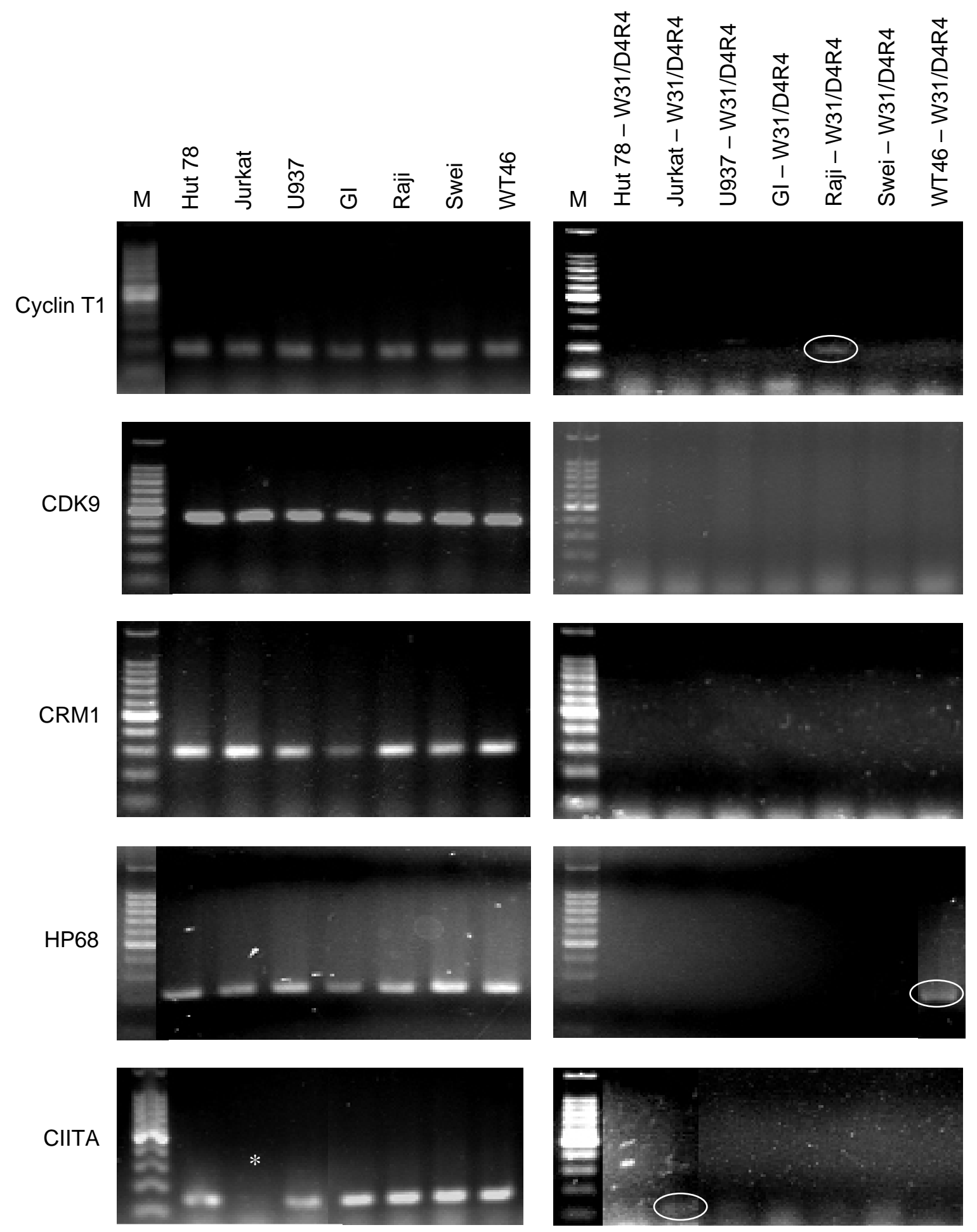

Figure 4 